\title{
SEISMIC DEMAND OF MASONRY INFILLS IN R.C. STRUCTURES ACCOUNTING FOR THE IN-PLANE/OUT-OF-PLANE INTERACTION
}

\author{
FABIO MAZZA' AND ANGELO DONNICI ${ }^{2}$ \\ ${ }^{1}$ Dipartimento di Ingegneria Civile, Università della Calabria, \\ 87036 Rende (CS), Italy \\ fabio.mazza@unical.it \\ ${ }^{2}$ Dipartimento di Ingegneria Civile, Università della Calabria, \\ 87036 Rende (CS), Italy \\ angelo.donnici@unical.it
}

Key words: Masonry Infills, In-Plane/Out-Of-Plane Interaction, Nonlinear Seismic Analysis

\begin{abstract}
The out-of-plane verification of unreinforced masonry infills (MIs) placed at different floor levels of a building is generally carried out through simplified methods, but seismic events in Italy (e.g. L'Aquila, 2009) and worldwide (e.g. Northridge, 1994) have highlighted that code provisions may result in wrong estimations of safety. The types of damage observed for MIs are usually a combination of, or an interaction between, in-plane (IP) and outof-plane (OOP) mechanisms. Specifically, the IP drift ratio is generally reduced at the upper storeys of buildings, where the OOP drift ratio increases due to an increase of seismic acceleration. Significant OOP damage may also take place at the lower storeys where the highest values of IP drift ratio are attained. The present work is aimed at identifying the effects of the IP and OOP nonlinear interaction of MIs on their seismic behaviour and acceleration demand. A five-element macro-model comprising four diagonal nonlinear beams and one (horizontal) central nonlinear truss for the prediction of the OOP and IP behaviour of MIs, respectively, is first implemented in a $\mathrm{C}++$ computer code for the nonlinear dynamic analysis of r.c. infilled framed structures. The proposed algorithm addresses the issue of nonlinear interaction by modifying stiffness and strength values of the MI in the OOP direction on the basis of simultaneous or prior IP damage and vice versa. Moreover, a lumped plasticity model describes the inelastic behaviour of r.c. frame members, including a 26-flat surface modelling of the axial load-biaxial bending moment elastic domain at the end sections where inelastic deformations are expected. A spatial one-bay multi-storey shear-type model is considered as equivalent to infilled r.c. framed buildings. In particular, the dependence of the results on variation of the following design parameters is considered: i.e. number of storeys; bay length; aspect ratio of MIs, with two leaves of clay hollow bricks, defined as the ratio between the panel length and height; strength level of the r.c. framed structure. Biaxial spectrum-compatible accelerograms are considered at ultimate limit states. A review of the current Italian (NTC18), European (EC8) and American (FEMA356) code provisions is performed by means of comparison with analyses results.
\end{abstract}




\section{INTRODUCTION}

Damage surveys that followed recent earthquakes (e.g. L'Aquila 2009, Central Italy 2016) highlighted poor seismic response of non-structural enclosure elements such as masonry infills (MIs). This was due to lack of attention to these elements in past seismic regulations as well as limited knowledge about their seismic behaviour. While the in-plane (IP) response of MIs has been widely studied in the last decades, only in recent years research interest moved towards the out-of-plane (OOP) one. Moreover, experimental tests showed that previous infill IP damage has a detrimental effect on OOP behaviour. Two main categories of infill models can be found in latest literature: i.e. fibre-section and beam/truss models [1]. Fibre-section models are effective in describing the nonlinear response of MIs but computationally expensive for nonlinear dynamic analyses of large structures. On the other hand, beam/truss elements allow a representation of the key features of the nonlinear behaviour of MIs in the IP and OOP directions and take into account the reduction of the OOP capacity produced by simultaneous or prior IP seismic damage. An upgraded infill macro-model is presented in this study, being able to simulate also the mutual IP $\leftrightarrow$ OOP interaction phenomenon. In this study, parametric analyses on r.c. infilled benchmark structures are carried out to explore the effects of a wide range of design parameters on infills seismic response: i.e. number of storeys; bay length; aspect ratio of MIs; strength level of the r.c. structure. Biaxial spectrum-compatible accelerograms are considered at ultimate limit states. In addition, results from nonlinear dynamic analyses are used to check the effectiveness of OOP verifications provided by the Italian (NTC18), European

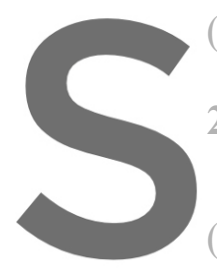
(EC8) and American

\section{2}

Each masonry panel is repres (central) element governs the nor
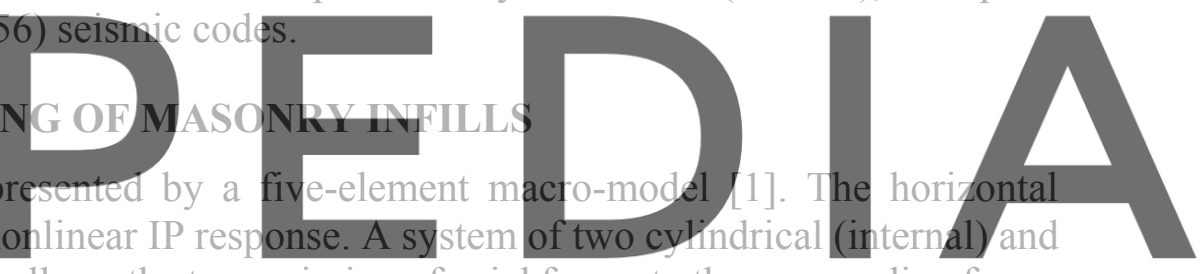

four spherical (external) hinges allows the transmission of axial forces to the surrounding frame

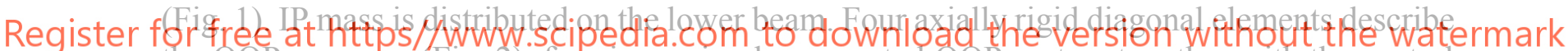
the OOP response (Fig. 2), forming a simply supported OOP system together with the central link. OOP first modal form participating mass $\mathrm{m}^{(\mathrm{OOP})}=0.81 \mathrm{~mm}[2]$ is divided equally between the two central nodes, thus allowing the generation of OOP inertial forces.
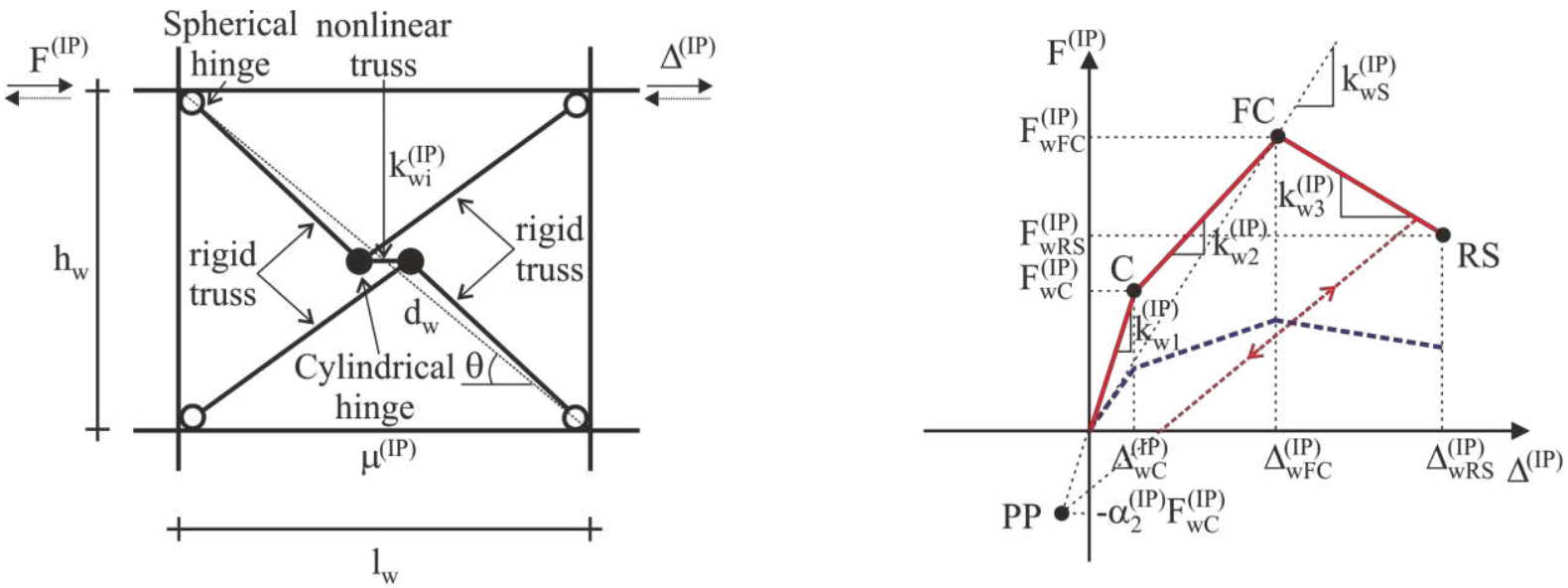

Figure 1: Nonlinear In-Plane (IP) model and OOP $\rightarrow$ IP interaction 

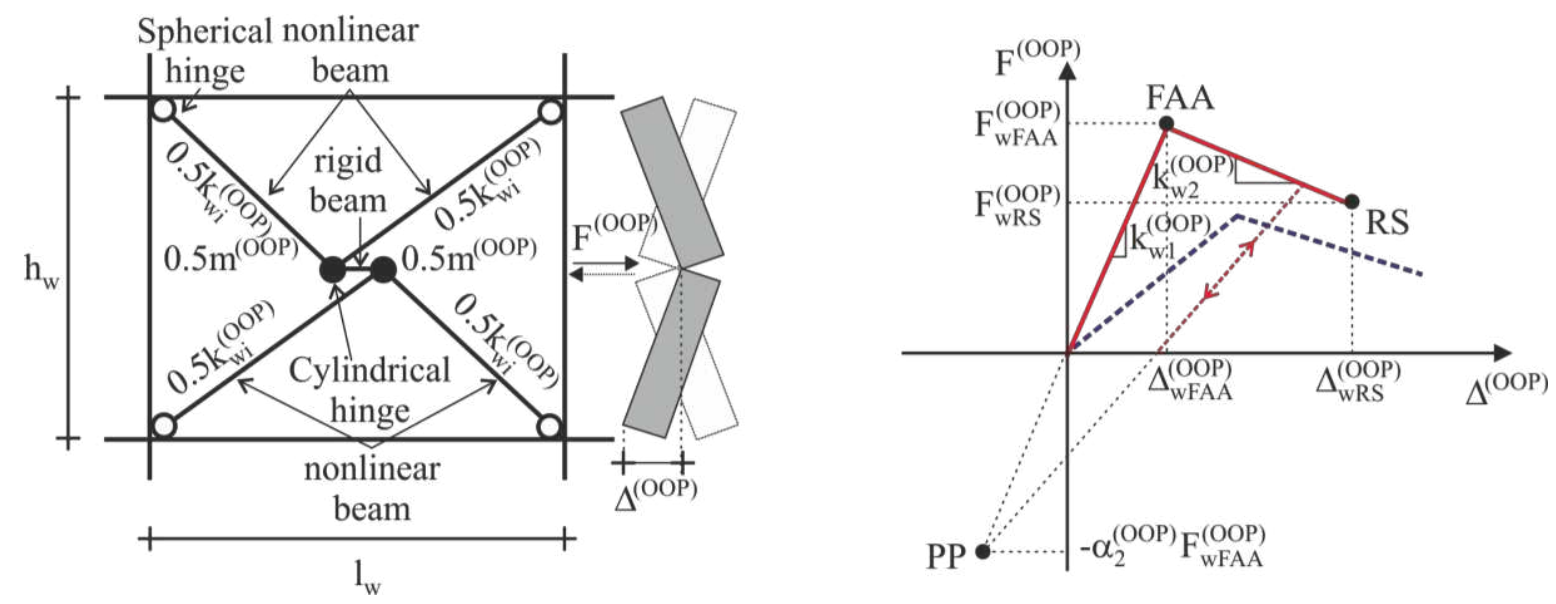

Figure 2: Nonlinear Out-of-Plane (OOP) model and IP $\rightarrow$ OOP interaction

\subsection{In-plane behaviour}

The IP behaviour is governed by a tri-linear lateral force (F)-interstorey $\operatorname{drift}(\Delta)$ backbone curve (Fig. 1, solid red line). First, the full-cracking (FC) strength point can be defined starting from maximum strength $\mathrm{F}_{\mathrm{wFC}}$ and secant-to-peak stiffness $\mathrm{k}_{\mathrm{wS}}$ values. Double leaf $(12+12) \mathrm{cm}$ infill typology, in accordance to Magenes definition [3], is selected to evaluate the peak infill strut response $\left(\sigma_{\mathrm{w}}\right)$, as minimum prediction between four failure mechanisms highlighted by Decanini et al. [4]. The secant stiffness $k_{w}$, that corresponds to this infill condition, is estimated
through Mainstone formulation [5] for strut width $b_{w}$. Ewv, $t_{w}, d_{w}$ are the Young nodulus in the
diagonal direction, in fill thickness and strut length, respectively.
\[ \frac{b_{w}}{d_{w}}=0.175 \cdot(\lambda \cdot h)^{-0.4}, k_{w}^{(P)}=E_{w \theta} \cdot b_{w}, t_{w} \cdot \cos ^{2} \theta / d_{w} \]

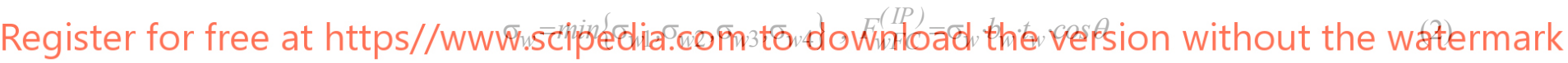

De Risi et al. [6] studied the cracking-to-maximum strength ratio, carrying out an extensive literature analysis. The assumed value 0.7 is in line with their suggestions. Setting a postcracking stiffness $\mathrm{k}_{\mathrm{w} 2}=0.15 \mathrm{k}_{\mathrm{w} 1}$, based on the infill model proposed by Cavaleri et al. [7] for clay masonry, it is possible to relate the initial stiffness $\mathrm{k}_{\mathrm{w} 1}$ to the secant one. The same authors provide two expressions for the strut ultimate strength $\left(\mathrm{F}_{\mathrm{wRS}}\right)$ and displacement $\left(\Delta_{\mathrm{wRS}}\right)$. Other backbone quantities are then univocally defined.

$$
\begin{gathered}
F_{w C}^{(I P)}=0.7 \cdot F_{w F C}^{(I P)}, k_{w 1}^{(I P)}=2.7 \cdot k_{w S}^{(I P)} \\
F_{w R S}^{(I P)}=0.7 \cdot F_{w F C}^{(I P)}, \Delta_{w R S}^{(I P)}=\frac{1}{0.02 \cdot \cos \theta} \cdot \ln \left(\frac{F_{w F C}^{(I P)}}{F_{w R S}^{(I P)}} \cdot e^{0.02 \cdot \cdot_{w F C}^{(I P)}}\right)
\end{gathered}
$$

\subsection{Out-of-plane behaviour}

The OOP backbone curve is expressed in terms of OOP force and drift. The latter is intended as OOP displacement divided by half of the infill height. The initial branch represents cracked OOP behaviour till maximum resistance while the softening branch leads to infill OOP collapse 
condition (Fig. 2, solid red line). The approach of Kadysiewski and Mosalam [2] gives a good approximation of the first branch stiffness $\mathrm{k}_{\mathrm{w} 1}$, as pointed out by Ricci et al. [8]. The maximum OOP strength is evaluated according to the lower-bound one-way arching formulation suggested by FEMA356 [9].

$$
\begin{gathered}
k_{w 1}^{(O O P)}=96 \cdot E_{w} \cdot I_{e q} / d_{w}{ }^{3}, I_{e q}=1.644 \cdot I_{w} \cdot\left(d_{w} / h_{w}\right)^{3}, I_{w}=\kappa \cdot l_{w} \cdot t_{w}{ }^{3} / 12 \\
s_{w}=h_{w} / t_{w}, q_{u}=0.7 \cdot f_{w v} \cdot \lambda_{2} / s_{w}, F_{w F A A}(O O P)=q_{u} \cdot l_{w} \cdot h_{w}
\end{gathered}
$$

The residual strength-to-peak strength ratio is based on experimental values from OOP tests available in literature [1] while the ultimate displacement $\Delta_{\mathrm{wRS}}$ is consistent with Ricci et al. [8] findings. A detailed description and definition of other IP and OOP parameters is reported in [1] together with the pivot hysteretic model adopted.

$$
F_{W R S}^{(O O P)}=0.6 \cdot F_{W F A A}^{(O O P)}, \Delta_{W R S}^{(O O P)}=3.7 \cdot \Delta_{W F A A}^{(O O P)}
$$

\subsection{In-plane-out-of-plane mutual interaction}

The novelty of the proposed model lies in the possibility to account for the effects of IP damage to the OOP response and vice versa. The OOP backbone is modified reducing its first branch stiffness and maximum strength when the predefined inter-storey drift (IDR) threshold is exceeded (Fig. 2, dashed blue line). Ricci et al. [10] provide the following interaction

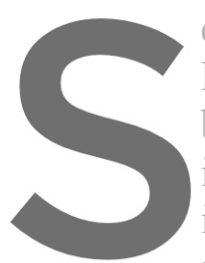
expressions for slender However, residual valurs backbone curve, that impossible OOP collaps infills (with thickness mentioned experimental results.
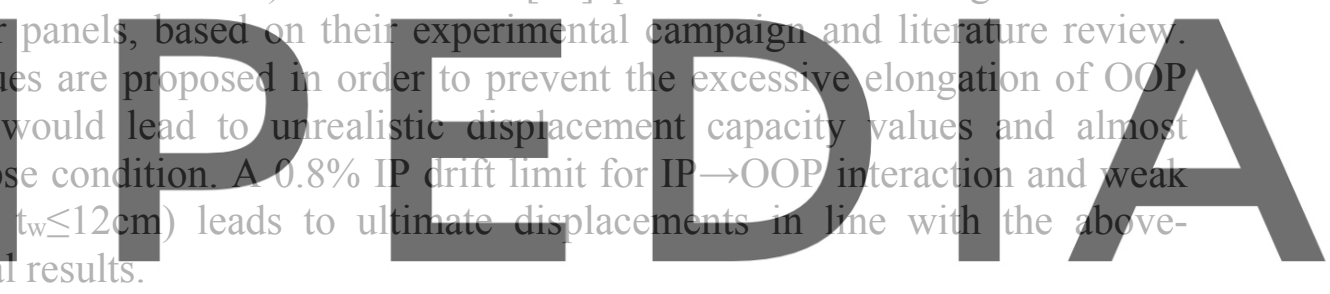

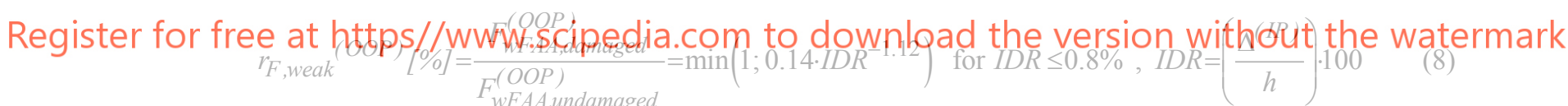

$$
r_{k, \text { weak }}^{(O O P)}[\%]=\frac{k_{w 1, \text { damaged }}^{(\text {OOP })}}{k_{w 1, \text { undamaged }}^{(\text {OOP }}}=\min \left(1 ; 0.05 \cdot I D R^{-1.51}\right) \text { for } I D R \leq 0.8 \%
$$

Available empirical expressions for the opposite $\mathrm{OOP} \rightarrow \mathrm{IP}$ interaction phenomenon do not seem to be rooted on an extensive database. Further and dedicated tests are surely needed in future research about the topic. On the other hand, Al-Chaar [11] focused on parametric numerical analyses on infill wall models and derived a relation between the OOP demand ratio (DR) and the IP maximum strength reduction, that will be used in the present work. IP backbone displacement is left unchanged as well as cracking and residual strength-to-peak strength ratios (Fig. 1, dashed blue line). As for the OOP interaction, an upper limit for the IP backbone degradation is set, at $90 \%$ of the OOP strength demand.

$$
r_{F, \text { weak }}^{(I P)}=\frac{F_{w F C, \text { damaged }}^{(I P)}}{F_{w F C, \text { undamaged }}^{(I P)}}=\min \left(1 ; 1+0.25 \cdot D R-1.25 \cdot(D R)^{2}\right) \text { for } D R \leq 0.90, D R=\left(\frac{F^{(O O P)}}{F_{w F A A}^{(O O P)}}\right)
$$




\section{R.C. BENCHMARK STRUCTURES}

A simplified model of r.c. framed structure is developed in order to carry out extensive parametric analyses. Specifically, benchmark structures representative of a wide range of r.c. framed residential buildings are selected. The generic structural model is composed of a single bay tridimensional shear-type frame with assigned floor mass $m$ ' and inter-storey height $h$ equal to $3 \mathrm{~m}$. Columns are kept square along the building height, reducing their dimensions every $2 \div 3$ floors. A cylindrical concrete strength equal to $20 \mathrm{MPa}$ and yield strength of steel equal to 450 $\mathrm{MPa}$ are assumed for r.c. cross-sections. A wide set of variabilities is assigned. First, the number of storeys $\left(n_{s}\right)$ can range from 3 to 8 . It influences the upper $\left(T_{\max }\right)$ and lower $\left(T_{\min }\right)$ limits of structural fundamental vibration period (Table 1). These limits are obtained as post-processing product of an extensive GIS aided survey over the residential building stock of Rende (Cosenza, Italy), that is assumed as design location. After setting the $\mathrm{n}_{\mathrm{s}}$ value, columns of each structure are sized to match one of first modal periods that belong to the selected range, that is discretized assuming a time step of $0.05 \mathrm{~s}$. Bay length equal to $4 \mathrm{~m}\left(\mathrm{~L}_{\mathrm{min}}\right)$ and $7 \mathrm{~m}(\mathrm{~L} \max )$ sets out floor area and infills aspect ratio (Fig. 3). Vertical loads are evenly distributed on surrounding beams.

Table 1: Range of the fundamental vibration period for each number of storeys
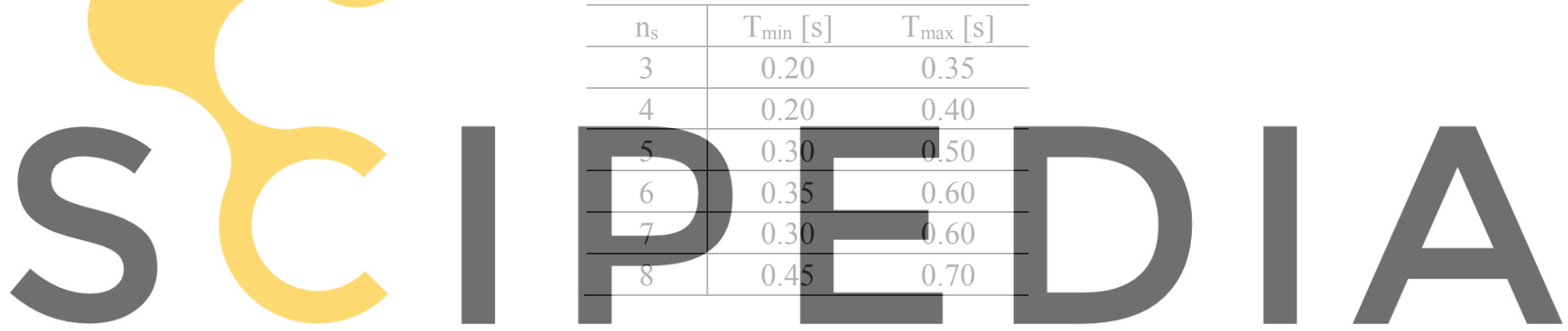

Benchmark structures are fully infilled, assuming typical $(12+12) \mathrm{cm}$ double leaf masonry

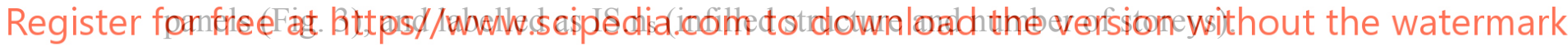
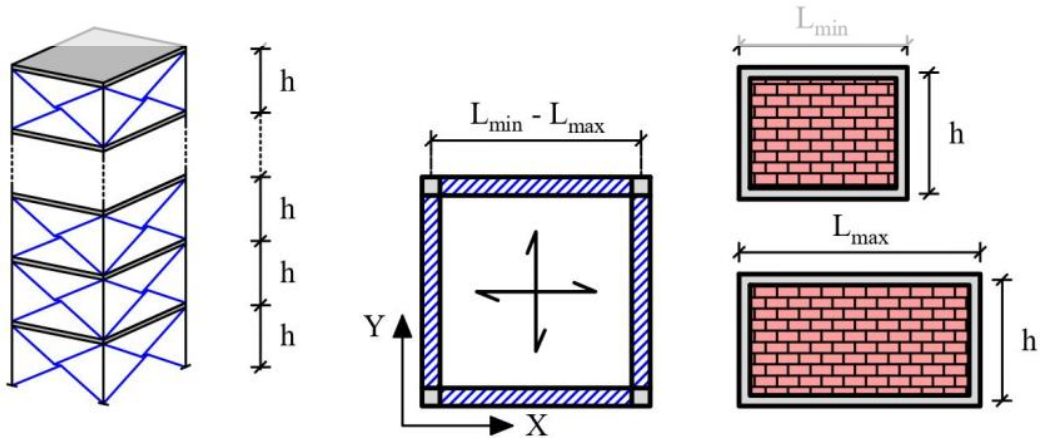

Figure 3: Benchmark structure layout

Once structural geometry is known, reinforcement design is carried out in compliance with current Italian code (NTC18), through a response spectrum approach. Elastic response spectrum is generated at Life Safety limit state for building class II, nominal design life $V_{R}=50$ years and subsoil class $\mathrm{C}$. Three behaviour factors are selected to evaluate the inelastic design spectrum: $\mathrm{q}=1.5$ (low ductility, LD), q=3.0 (medium ductility, MD) and q=4.5 (high ductility, HD). 
As the final step, it is necessary to define a procedure to evaluate the model floor mass $m$ '. The floor area of a real r.c. framed building is divided into fields by floor beams. Each field corresponds to a real field mass $\mathrm{m}$. Given the assumptions of constant floor bay length, square and identical floor columns and shear-type structural behaviour, the equivalence between floor mass-to-stiffness ratio of the real structure and benchmark model can be expressed as:

$$
\frac{m}{k}=\frac{m^{\prime}}{k^{\prime}} \Rightarrow R_{m^{\prime} m}=\frac{m^{\prime}}{m}=\frac{4 \cdot\left(n_{b, x} \cdot n_{b, y}\right)}{\left(n_{b, x}+1\right) \cdot\left(n_{b, y}+1\right)}
$$

In this way, the floor stiffness can be replaced by the number of floor columns, which depends on the number of bays in the in-plan $\mathrm{x}\left(\mathrm{n}_{\mathrm{b}, \mathrm{x}}\right)$ and $\mathrm{y}\left(\mathrm{n}_{\mathrm{b}, \mathrm{y}}\right)$ directions. The result is a two variable function that represents the model mass to field mass ratio $\left(\mathrm{R}_{\mathrm{m}}\right.$ 'm). Domain restrictions $\mathrm{n}_{\mathrm{b}, \min }=2$ and $\mathrm{n}_{\mathrm{b}, \max }=8$ prevent from considering too small or technically unfeasible buildings. The mean surface value can be assumed equal to 2.5 and will be used for analyses.

Once every parameter is set, a MATLAB algorithm creates the structural model input file for nonlinear dynamic analyses. Workflow of this code is summarised in Fig. 4.
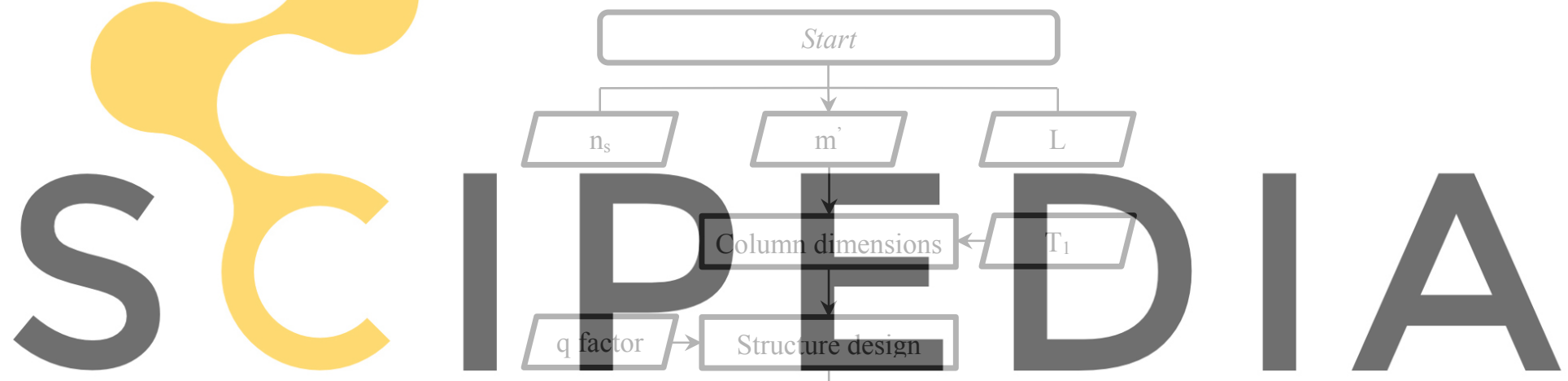

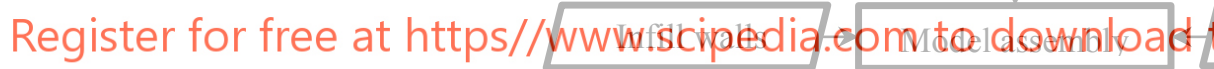

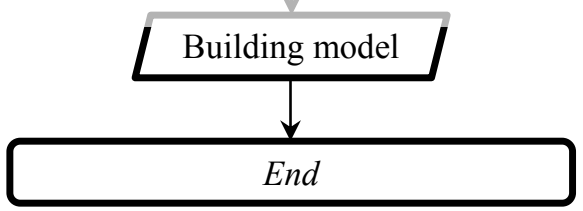

Figure 4: Flow chart of the algorithm for assembly of a benchmark structure

\section{NUMERICAL RESULTS}

The new infill macro-model is implemented in a $\mathrm{C}++$ code for nonlinear dynamic analyses of 3D benchmark structures. Double-leaf $(12+12) \mathrm{cm}$ masonry panels are considered for totally infilled r.c. framed structures. A lumped plasticity model is assumed for r.c. frame members. Nonlinear seismic analyses are carried out twice in order to compare results for single and mutual IP-OOP interaction of MIs. Further information about single interaction modelling can be found in [1]. Given the wide set of variabilities, a single pair of spectrum-compatible acceleration histories is considered. In detail, two artificial ground motions are generated to match NTC18 elastic response spectra at Life Safety (LS) and Collapse Prevention (CP) limit 
states, assuming Rende (Italy) as location, building usage class II, nominal design life $V_{R}=50$ years, subsoil class $\mathrm{C}$ and far-field condition. Different layers of results can be obtained from parametric analyses. For the sake of brevity, only the most important ones will be discussed.

First, envelope results between $\mathrm{L}_{\min }$ and $\mathrm{L}_{\max }$ for the LS and single IP $\rightarrow \mathrm{OOP}$ interaction conditions are reported in Figs. 5 and 7, in terms of IP and OOP drift, respectively. Maximum drifts are evaluated over the predefined fundamental vibration periods range for each behaviour factor value and number of storeys. It is useful to introduce additional graphs showing the storey related to a generic IP or OOP maximum value (Figs. 6 and 8). The IP drift tends to increase for higher $\mathrm{T}_{1}$ values, especially in the case of low-rise buildings, where LD curves show the expected lowest values only if this maximum is registered at first storey. However, higher seismic intensity and building height induce the concentration of IP demand at intermediate storeys. In this way, envelope curves of the LD structures tend to assume a position in-between MD and HD curves, characterized by first level predominance and lower higher modes impact on maximum IP drift position. The highest values of maximum OOP drift are attained by LD buildings, due to lower structural damage (Fig. 7). The OOP response is heavily affected by both the interaction phenomenon intensity and panel position along the height of the building. Higher IP drift values mean higher OOP strength and stiffness reductions. At the same time, OOP acceleration generally increases with panel position. This is clear for LD structures, where higher accelerations and OOP drifts are attained at top level (Fig. 8) and interaction effect is negligible (for low-rise structures). Intermediate storeys become predominant as the number of levels increases. On the other hand, HD structures show the highest IP drift values, therefore the OOP interaction is MIs increases, exceeding to OOP vulnerability tor while this vulnerability area modes influence on the
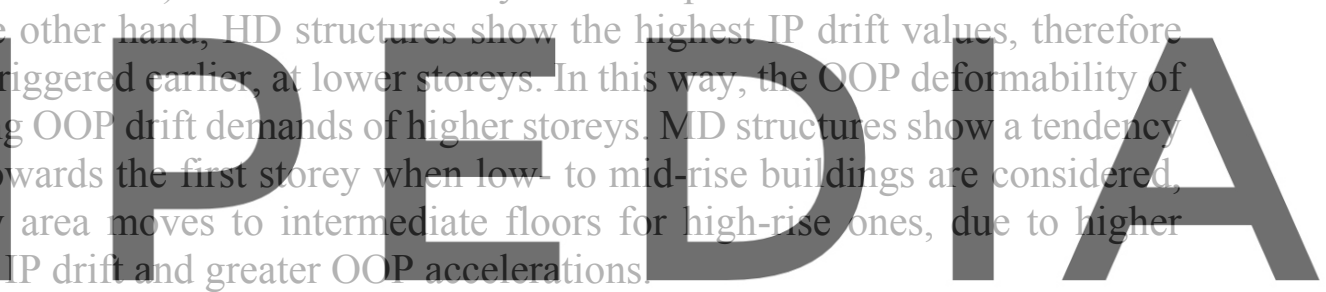

Influence of the behaviour factor on infills response becomes evident when results along the

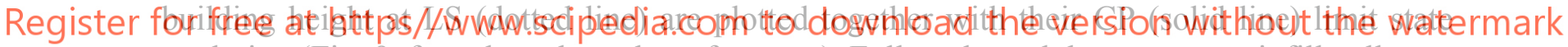
evolution (Fig. 9, for selected number of storeys). Fully coloured dots represent infill collapse. HD structures with limited height tend to concentrate IP drift demands at first storey, where OOP infill overturning due to interaction effect occurs before IP collapse. Two vulnerability zones can be highlighted if MD structures are pushed to $\mathrm{CP}$ seismic intensity as building moves towards high-rise typology. IP drifts at first and intermediate storeys prevail over others, triggering infill interaction and OOP collapse. The resulting IP storey stiffness reduction makes these levels susceptible to soft-storey mechanism. LD structures show the highest number of infill failures. As the number of storeys raises, IP drift demand is uniformly spread along the height and interaction phenomenon affects almost all panels, leading to several failures and overall increase in IP deformability.

Mutual IP $\leftrightarrow$ OOP interaction (Fig. 10, solid line) generally has a detrimental effect on both IP and OOP responses when compared to single IP $\rightarrow$ OOP interaction (dashed line). Infills damage and collapses are exacerbated for all values of the behaviour factor. This becomes evident in terms of infill displacement time histories, that are plotted in Fig. 11 together with displacement domains evaluated in line with FEMA356 for different frame-infill conditions.

International standards provide simplified formulations to compute floor response spectra. Thus, infill OOP acceleration demand can be estimated, depending on its fundamental period. 

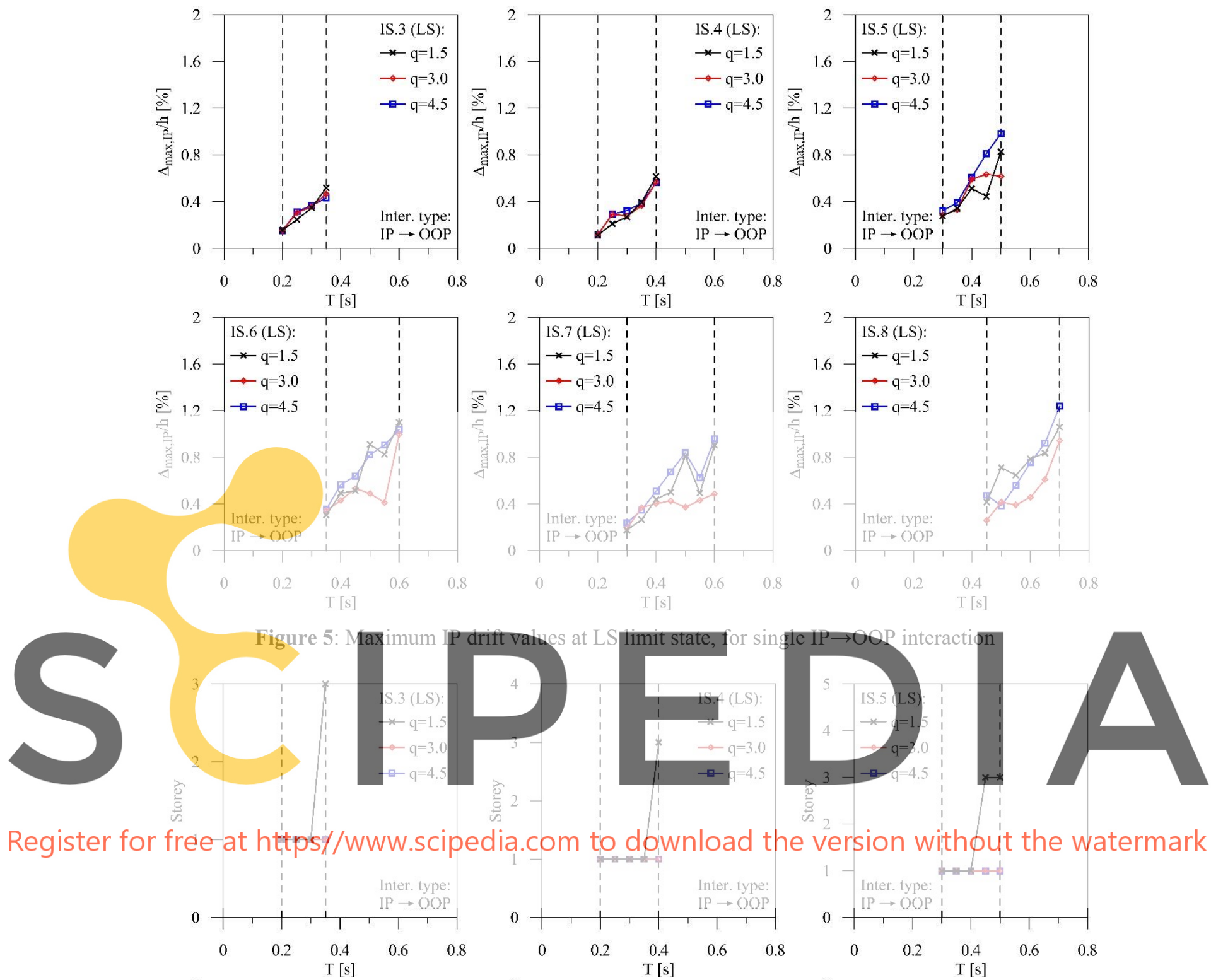

Register for free at https//www.scipedia.com to download the version without the watermark
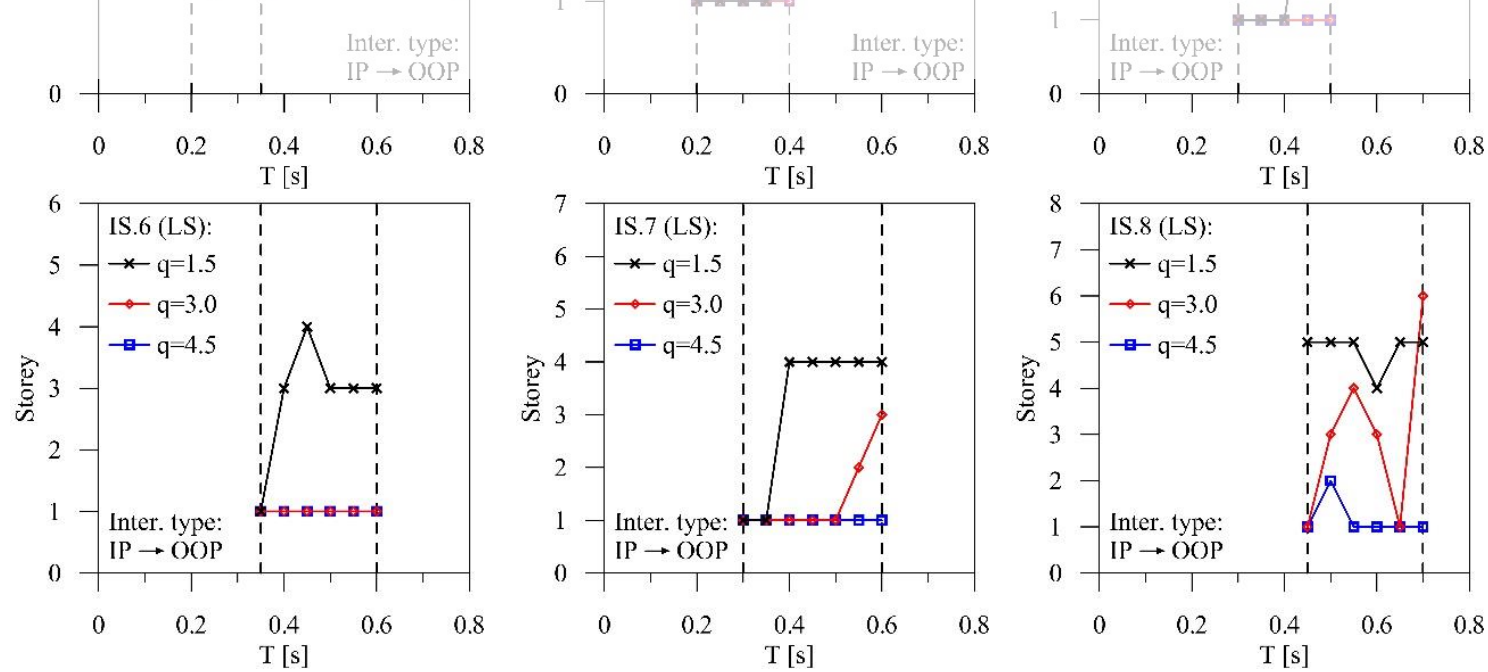

Figure 6: Storey associated with maximum IP drift at LS limit state, for single IP $\rightarrow \mathrm{OOP}$ interaction 

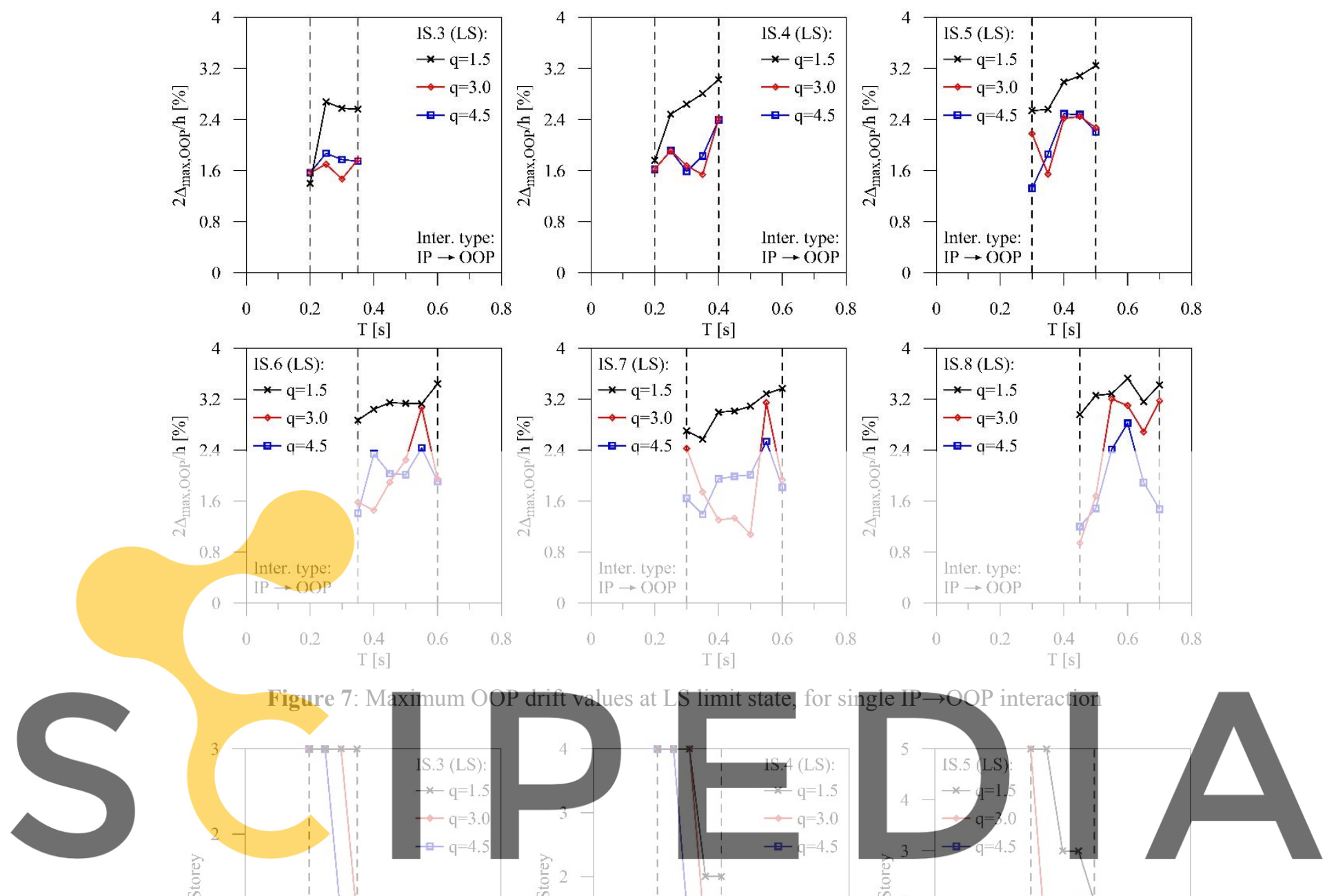

Register for free at https//www.scipedia.com to download the version without the watermark
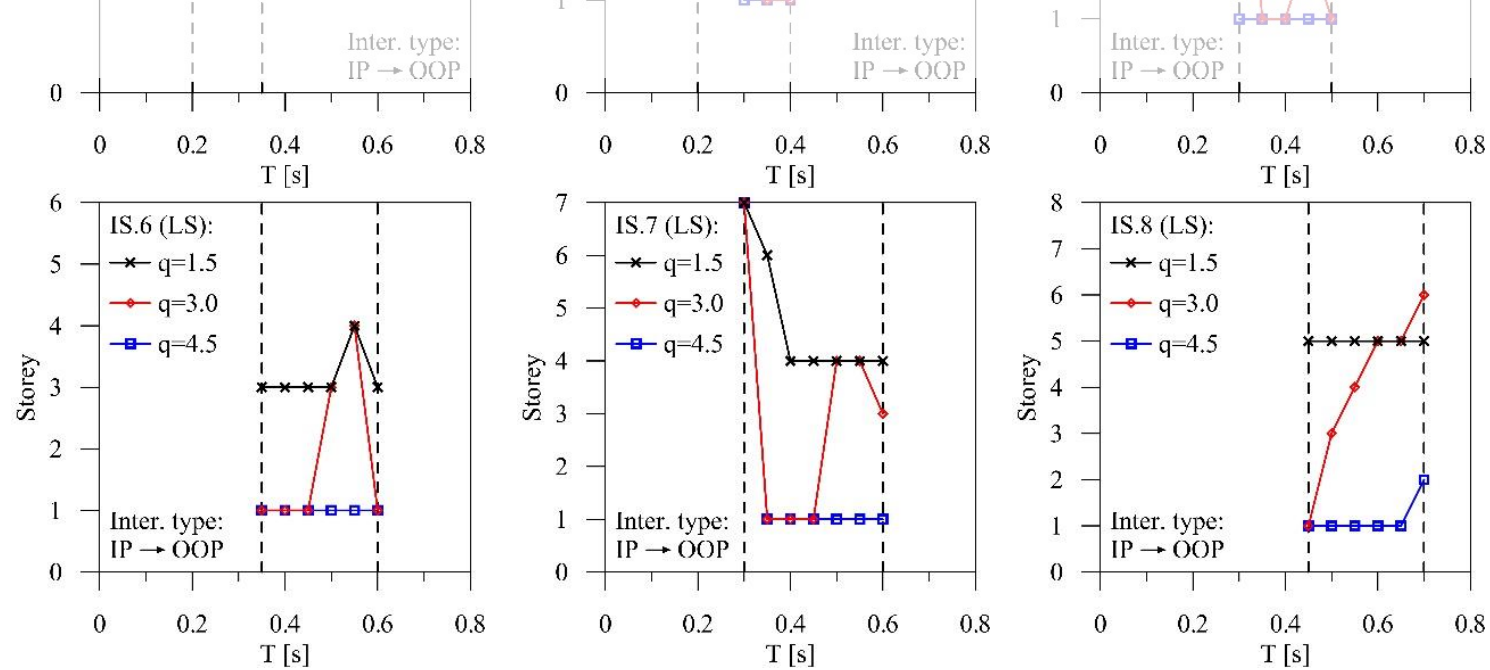

Figure 8: Storey associated with maximum OOP drift at LS limit state, for single $\mathrm{IP} \rightarrow \mathrm{OOP}$ interaction 

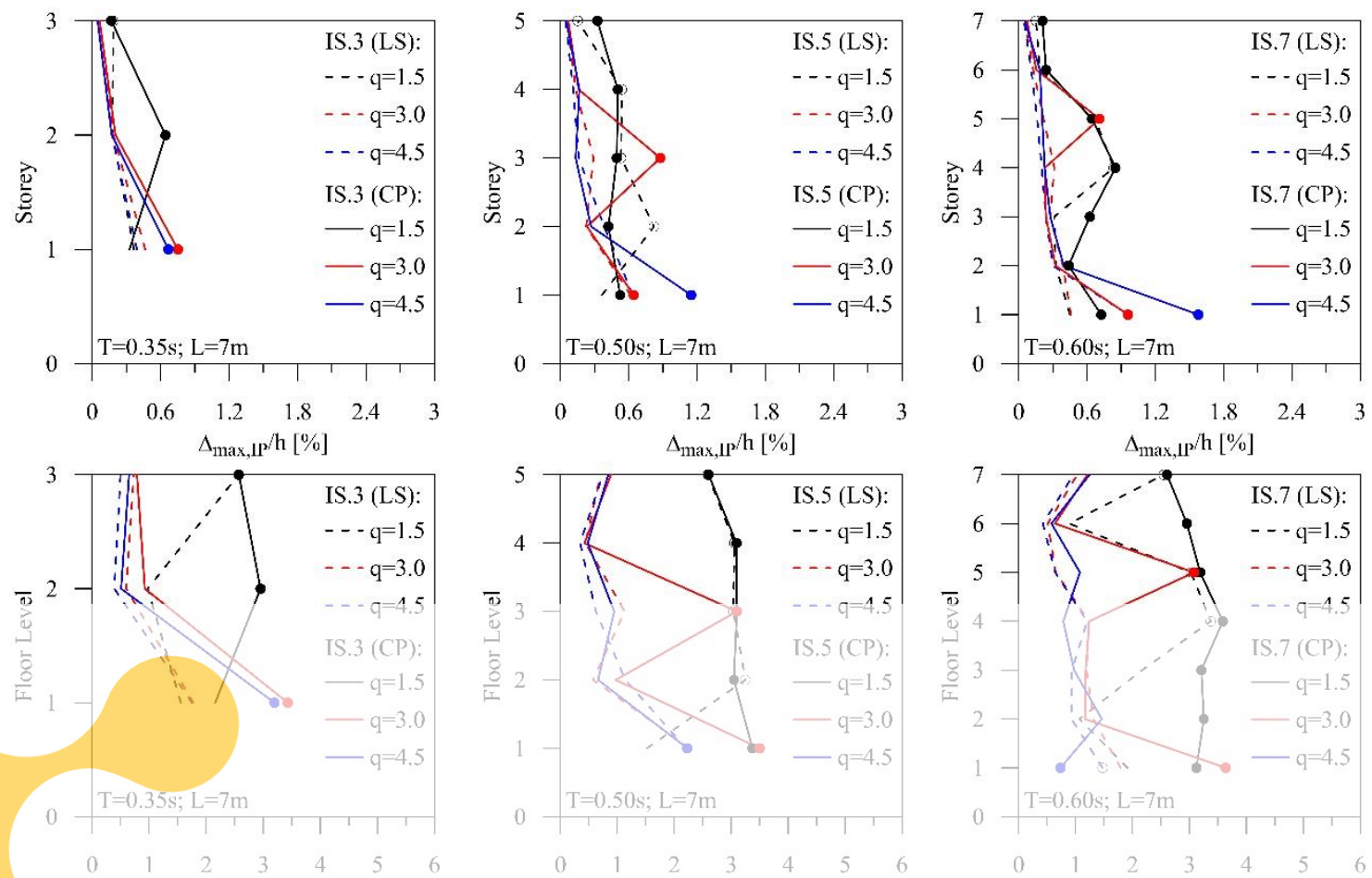

$2 \triangle_{\max , 0 O P} / \mathrm{h}[\%]$

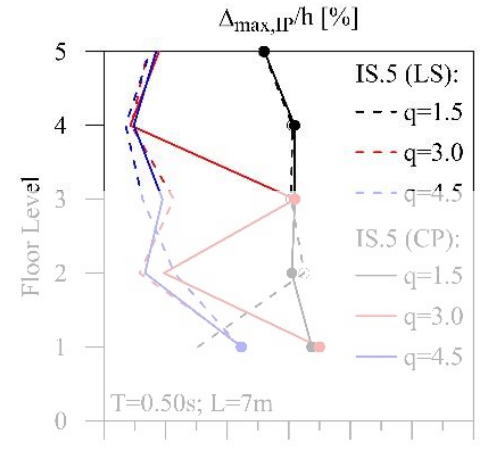



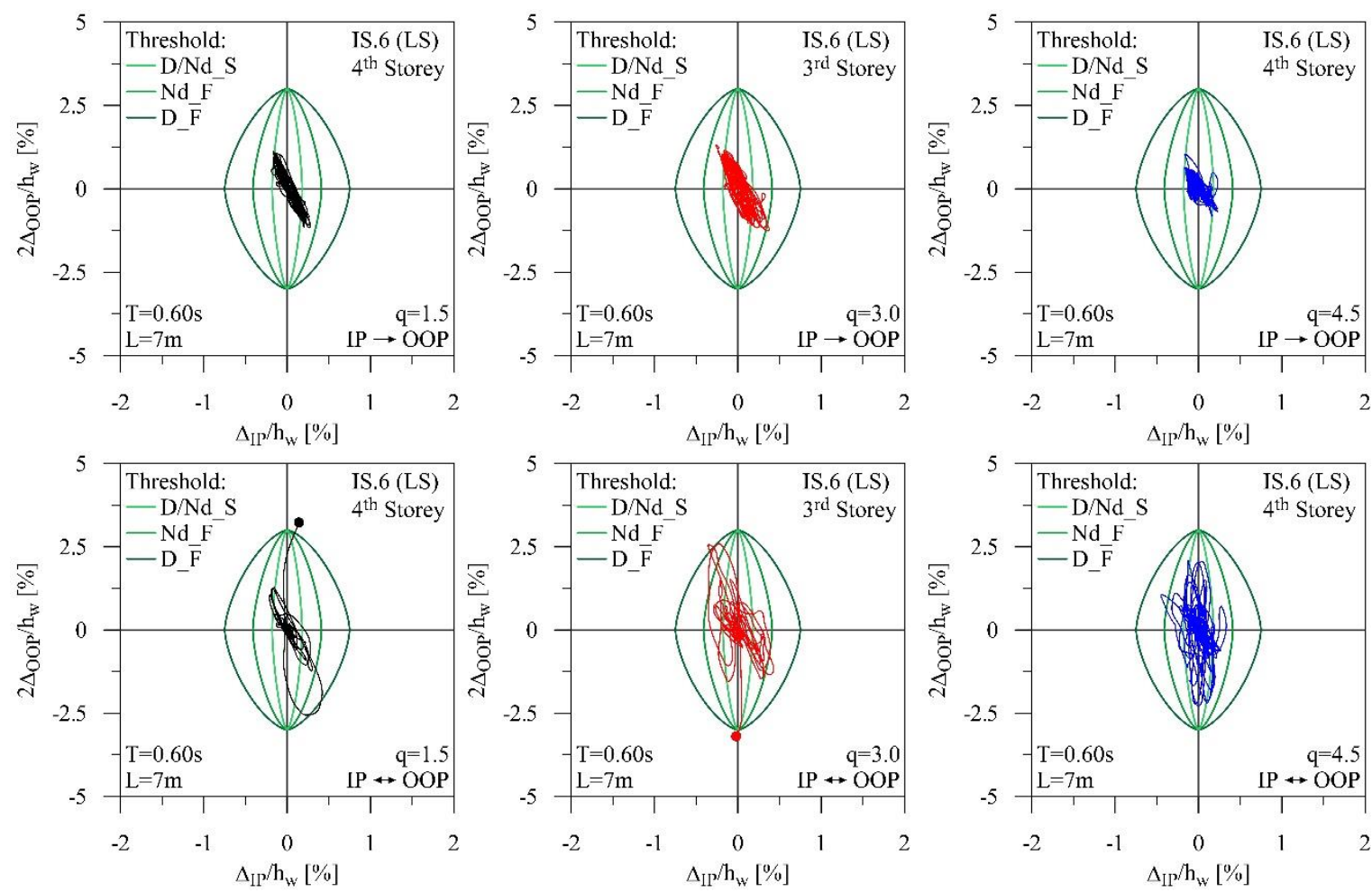

Figure 11: Displacement time histories of IS.6 for LS limit state and single IP $\rightarrow$ OOP (top) or mutual IP $\leftrightarrow$ OOP (bottom) interaction: Ductile/Non ductile frame - Stiff/Flexible infill limit domains
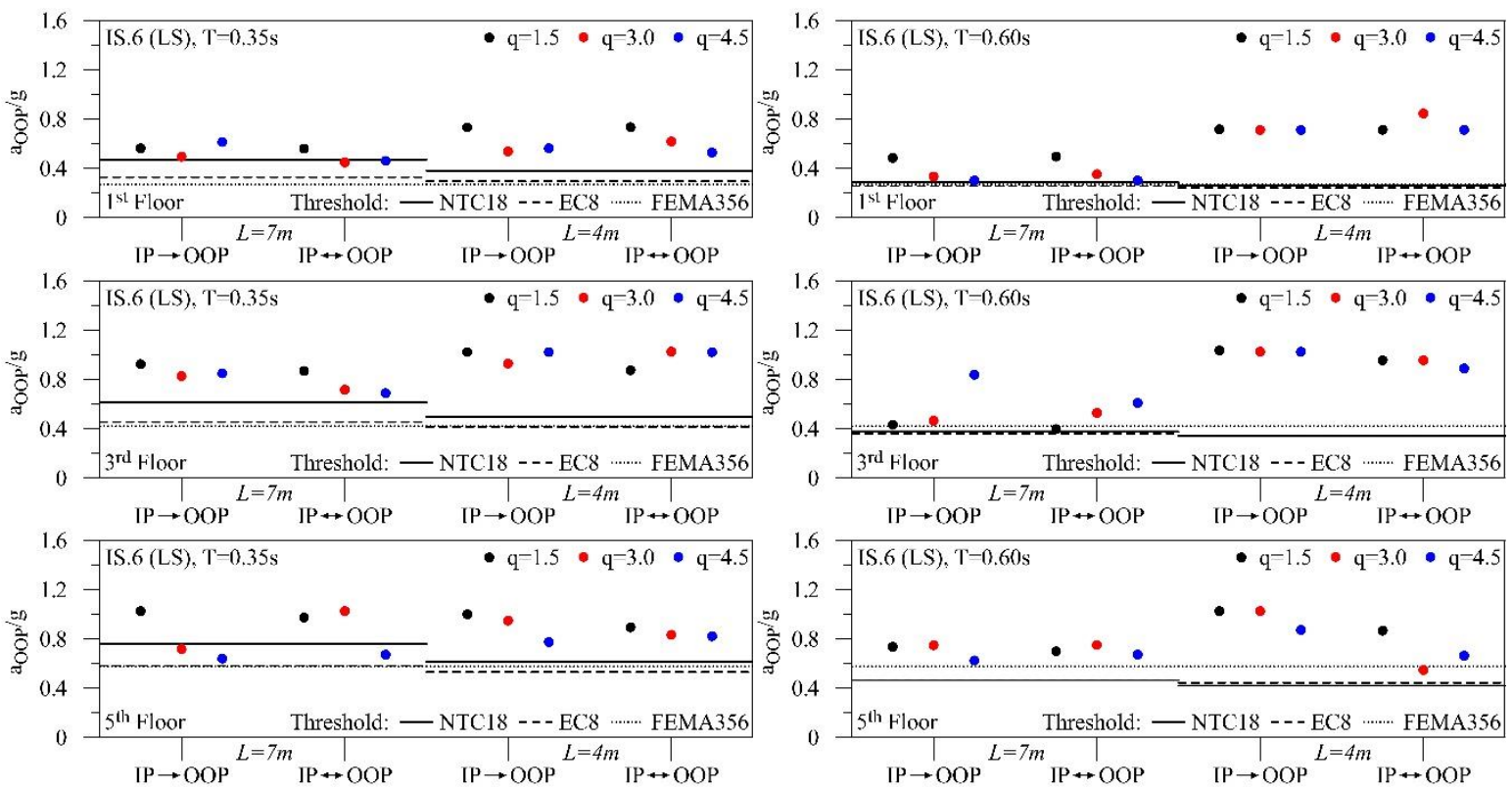

Figure 12: Comparison of maximum OOP acceleration values (IS.6, LS), at selected floors, and international standards predictions: $\mathrm{T}_{\min }$ (left side) and $\mathrm{T}_{\max }$ (right side) for both $\mathrm{L}_{\min }$ and $\mathrm{L}_{\max }$

Italian NTC18 [12], European EC8 [13] and American FEMA356 [9] predictions tend to underestimate the OOP acceleration demand (Fig. 12), showing room for improvement. 


\section{CONCLUSIONS}

The proposed infill macro-model is applied to r.c. benchmark structures in order to perform a wide range of parametric analyses, being able to represent single (IP $\rightarrow \mathrm{OOP})$ and mutual (IP↔OOP) interaction phenomena of MIs. Concluding briefly on the results:

- structural behaviour factor $q$ has a significant influence on infills response, as it governs both the IP drift inelastic evolution and OOP acceleration demand;

- $\quad$ mutual IP $\leftrightarrow$ OOP interaction generally leads to worse results when compared to single interaction modelling, amplifying drifts and increasing non-structural collapses;

- OOP acceleration demands evaluated in compliance with three international standards seem to be not on the safe side, especially if the bay length decreases.

\section{REFERENCES}

[1] Mazza, F., Donnici, A. In-plane and out-of-plane seismic damage of masonry infills in existing r.c. structures: the case study of De Gasperi-Battaglia school in Norcia. Bull Earthq Eng (2021) 19:345-376.

[2] Kadysiewski, S., Mosalam, K.M. Modelling of Unreinforced Masonry Infill Walls Considering In-Plane and Out-of-Plane Interaction. Berkeley, California, USA: Pacific Earthquake Engineering Research Center (2009).

[3] Hak, S., Morandi P., Magenes, G. and Sullivan, T.G. Damage Control for Clay Masonry Infills in the Design of RC Frame Structures. J Earthq Eng (2012) S1:1-35.

[4] Bertoldi, S.H., Decanini L.D. and Gavarini, C. Telai tamponati soggetti ad azioni sismiche, un modello semplificato: confronto sperimentale e numerico. Proceedings of the VI National Conference on Earthq Eng, ANIDIS, Perugia, Italy (1993): 815-24.

[5] Mainstone, R.J. Supplementary note on the stiffness and strength of infilled frames. Building Research Station, UK, CP 13/74. NCEER (1974).

[6] De Risi, M.T., Del Gaudio, C., Ricci, P., Verderame, G.M. In-plane behaviour and damage assessment of masonry infills with hollow clay bricks in RC frames. Eng Struct (2018) 168:257-275.

[7] Cavaleri, L., Di Trapani, F. Cyclic response of masonry infilled RC frames: experimental results and simplified modelling. Soil Dyn Earthq Eng (2014) 65:224-242.

[8] Ricci, P., Di Domenico, M., Verderame, G.M. Empirical-based out-of-plane URM infill wall model accounting for the interaction with in-plane demand. Earthq Eng Struct dyn (2018) 47(3):802-827.

[9] FEMA356. Prestandard and Commentary for the Seismic Rehabilitation of Buildings. Washington, DC: Federal Emergency Management Agency (2000).

[10] Ricci, P., Di Domenico, M., Verderame, G.M. Experimental assessment of the inplane/out-of-plane interaction in unreinforced masonry infill walls. Eng Struct (2018) 173:960-978.

[11] Al-Chaar, G. Evaluating strength and stiffness of unreinforced masonry infill structures. Engineer research and development center Champaign, Illinois. CERL (2002).

[12] NTC18, Norme Tecniche per le Costruzioni. G.U. del 20/02/2018, Supplemento ordinario n.42 (2018, in Italian).

[13] EC8, Eurocode 8. Design of Structures for Earthquake Resistance - Part 3: Assessment and retrofitting of buildings. C.E.N., European Committee for Standardization (2004). 